hyperresponsiveness to mannitol and exhaled NO. J Asthma 2009:46:606-12.

7. Pin I, Radford S, Kolendowicz R, et al. Airway inflammation in symptomatic and asymptomatic children with methacholine hyperresponsiveness. Eur Respir J 1993:6:1249-56.

8. Gibson PG, Simpson JL, Hankin R, et al. Relationship between induced sputum eosinophils and the clinical pattern of childhood asthma. Thorax 2003;58:116-21.

9. Green RH, Brightling CE, McKenna S, et al. Asthma exacerbations and sputum eosinophil counts: a randomised controlled trial. Lancet 2002;360:1715-21.

10. He XY, Simpson JL, Wang F. Inflammatory phenotypes in stable and acute childhood asthma. Paediatr Respir Rev 2011;12:165-9.

11. Cowan DC, Cowan JO, Palmay R, et al. Taylor DREffects of steroid therapy on inflammatory cell subtypes in asthma. Thorax 2010;65:384-90.

12. Pavord ID, Brightling CE, Woltmann G, et al. Noneosinophilic corticosteroid unresponsive asthma. Lancet 1999;353:2213-14.

13. Berry M, Morgan A, Shaw DE, et al. Pathological features and inhaled corticosteroid response of eosinophilic and non-eosinophilic asthma. Thorax 2007;62:1043-9.

14. Lex C, Jenkins G, Wilson NM, et al. Does sputum eosinophilia predict the response to systemic corticosteroids in children with difficult asthma? Pediatr Pulmonol 2007:42:298-303.

15. ten Brinke A, Zwinderman AH, Sterk PJ, et al. "Refractory" eosinophilic airway inflammation in severe asthma: effect of parenteral corticosteroids. Am J Respir Crit Care Med 2004;170:601-5

16. Bossley CJ, Saglani S, Kavanagh C, et al Corticosteroid responsiveness and clinical characteristics in childhood difficult asthma. Eur Respir J 2009;34:1052-9.

17. Pizzichini E, Pizzichini MM, Efthimiadis A, et al. Indices of airway inflammation in induced sputum: reproducibility and validity of cell and fluid-phase measurements. Am J Respir Crit Care Med 1996;154:308-17

18. Simpson JL, McElduff P, Gibson PG. Assessment and reproducibility of non-eosinophilic asthma using induced sputum. Respiration 2010;79:147-51.

19. Jayaram L, Pizzichini MM, Cook RJ, et al. Determining asthma treatment by monitoring sputum cell counts: effect on exacerbations. Eur Respir $\mathrm{J}$ 2006:27:483-94.

20. Ward C, Pais M, Bish R, et al. Airway inflammation basement membrane thickening and bronchial hyperresponsiveness in asthma. Thorax 2002; 57:309-16.

21. Fleming L, Wilson $\mathrm{N}$, Regamey $\mathrm{N}$, et al. Use of sputum eosinophil counts to guide management in children with severe asthma. Thorax 2012;67:193-8

22. Haldar $\mathbf{P}$, Pavord ID, Shaw DE, et al. Cluster analysis and clinical asthma phenotypes. Am J Respir Crit Care Med 2008;178:218-24.

23. Moore WC, Meyers DA, Wenzel SE, et al; National Heart, Lung, and Blood Institute's Severe asthma Research Program. Identification of asthma phenotypes using cluster analysis in the severe asthma Research Program. Am J Respir Crit Care Med 2010;181:315-23.

24. Anderson GP. Endotyping asthma: new insights into key pathogenic mechanisms in a complex, heterogeneous disease. Lancet 2008;372:1107-19.

\title{
Bronchodilator responsiveness: interpret with caution
}

\section{James Fingleton, ${ }^{1}$ Mark Weatherall, ${ }^{2}$ Richard Beasley ${ }^{1}$}

Bronchodilator responsiveness (BDR) is widely considered to be a key diagnostic criterion for asthma, and is used to differentiate asthma from chronic obstructive pulmonary disease (COPD). Currently, the threshold of a $12 \%$ increase in $\mathrm{FEV}_{1}$ from baseline following inhaled salbutamol, with at least a $200 \mathrm{ml}$ increase in absolute terms, is recommended as a response indicative of asthma, ${ }^{1}$ although recent British guidelines recognise the poor discriminatory function of this criterion. $^{2}$ Thus, despite this criterion being commonly used in clinical practice, there is uncertainty regarding its clinical utility, in particular its ability to differentiate asthma from COPD, or indeed, normal subjects.

One approach to enable a better understanding of the clinical utility of BDR is to determine the worldwide distribution of

\footnotetext{
${ }^{1}$ Medical Research Institute of New Zealand, Wellington, New Zealand; ${ }^{2}$ University of Otago Wellington, Wellington, New Zealand

Correspondence to Professor Richard Beasley, Medical Research Institute of New Zealand, Private Bag 7902, Newtown, Wellington 6242, New Zealand; richard.beasley@mrinz.ac.nz
}

BDR in health and disease, which has been undertaken by Tan and colleagues, and reported in Thorax. ${ }^{3}$ The authors report $\mathrm{BDR}$ in terms of change in $\mathrm{FEV}_{1}$ and FVC following $200 \mu \mathrm{g}$ of salbutamol delivered by metered dose inhaler via a spacer, in around 10000 adults aged 40 years and older from 14 countries in North America, Europe, Asia and Africa who participated in the Burden of Obstructive Lung Disease study. The Burden of Obstructive Lung Disease methodology is robust and has many strengths, not the least of which is its multi-national nature and the central review of all spirometry, which increases confidence in the reliability of the lung function values obtained. The results of this study are, therefore, likely to be unbiased, and precise estimates of the populations described. The authors report that the most reliable metric of BDR was the change in $\mathrm{FEV}_{1}$ relative to predicted $\mathrm{FEV}_{1}\left(\Delta \mathrm{FEV}_{1} \mathrm{p}\right)$. In healthy non-smokers, the threshold or upper limit of normality for $\Delta \mathrm{FEV}_{1} \mathrm{p}$ was $10 \%$ without heterogeneity across populations. The authors also report the more commonly used measure of change in $\mathrm{FEV}_{1}$ from baseline, and give a threshold of $12 \%$.
The values reported are consistent with the current ATS/ERS Task Force cut-offs for defining a clinically significant bronchodilator response. ${ }^{4}$ The authors propose that this strengthens the applicability of this measure for global interpretation of bronchodilator testing on the basis that values above this cut-off are beyond 95\% of the distribution of healthy individuals and, as such, can be considered 'abnormal,' thus reflecting the presence of disease.

Although it is also proposed that such a cut-off discriminates healthy subjects from obstructed individuals, this unfortunately is not the case. Further analysis of their data indicates that BDR discriminates poorly between healthy subjects and individuals with airflow obstruction regardless of comorbid asthma $\left(\mathrm{FEV}_{1} / \mathrm{FVC}\right.$ $<0.7, \mathrm{FEV}_{1} \%$ predicted $<80 \%$ ). The authors found that BDR was consistent with a Gaussian (normal) distribution. The mean (SD) values for BDR expressed as $\triangle \mathrm{FEV}_{1} \mathrm{p}$ in healthy individuals was $2.6 \%$ (4.8) and $4.2 \%(5.7)$ in obstructed individuals. The Gaussian distribution gives the proportion of those above the cut-off of $10 \%$ as $6.1 \%$ (healthy), and $15.4 \%$ (obstructed). For healthy versus obstructed, the sensitivity was $15.4 \%$, specificity $93.9 \%$, likelihood ratio test positive 2.5, and test negative 0.9 . These values, particularly for likelihood ratio negative, are not consistent with a good discriminatory test. Values for likelihood ratio positive and negative that are considered to represent clinically relevant changes in post-test probabilities of disease are 5 and 0.2 , respectively. 
Likewise, in individuals with obstruction, the proposed cut-off levels discriminate poorly between self-reported asthma and COPD. When BDR was expressed as change in $\mathrm{FEV}_{1}$ from baseline, the mean (SD) value was $7.7 \%(11.0)$ in COPD and, by calculation, $11.9 \%$ (14.1) in selfreported asthma. The Gaussian distribution gives the proportion of those above the cut-off of $12 \%$, the value recommended for use in clinical practice to diagnose asthma, ${ }^{1}$ as $34.8 \%$ in COPD and $49.7 \%$ in self-reported asthma. This is consistent with studies which have shown that there is a large overlap of individual $\mathrm{BDR}$ in patient subgroups of asthma and COPD, despite significant differences in mean response. ${ }^{5-7}$ Among those with airflow obstruction, and considering self-reported asthma versus COPD, using a $12 \%$ change from baseline as the cut-off value, the sensitivity for asthma was $49.7 \%$, specificity $65.2 \%$, likelihood ratio test positive 1.4 , and test negative 0.8 . Selection of other cut-off levels is unlikely to improve performance because of the considerable overlap in the levels of BDR between COPD and asthma. However, it would be possible for the authors to construct ROC curves to determine the sensitivity and specificity of different cut-off values to address this question.

Another desirable characteristic for diagnostic tests is repeatability when measured over time. From the Lung Health Survey, it was reported that there is substantial annual variability of BDR. ${ }^{8}$ Similarly, large within-subject variability of BDR was observed in the Inhaled Steroids in Obstructive Lung DiseasE (ISOLDE) study in which about $50 \%$ of patients with moderate to severe COPD changed responder status between study visits. 9 Therefore, BDR is a poorly repeatable characteristic of individual patients with airways obstruction.
BDR has also been widely used to assess potential treatment response. However, the lack of an acute BDR does not preclude subsequent benefit from maintenance inhaled long-acting bronchodilator therapy. ${ }^{10}$

These findings have implications not only for diagnosis but also in the generalisability of randomised controlled trials (RCTs) on which both guidelines and clinical practice are based. The understandable desire to have objective criteria governing the selection of trial participants leads to the unintended consequence that the results of such trials have limited generalisability to the majority of patients with airways disease. Most asthma RCTs require subjects to have $\mathrm{BDR}$ of at least $15 \%$ increase in $\mathrm{FEV}_{1}$ from baseline, and COPD RCTs require subjects to have $<10 \%$ increase in $\mathrm{FEV}_{1}$. In a random population, these criteria alone result in around $76 \%$ of adults with asthma and $29 \%$ of adults with COPD being ineligible for the major RCTs on which their management has been based. $^{11} 12$

In conclusion, there is considerable overlap in BDR in health and disease, and between asthma and COPD. It has recently been argued that 'spirometry is an essential tool in patient evaluation, but dangerous for disease diagnosis, and the term, COPD, should only be used in the appropriate clinical (diagnostic) context'. ${ }^{13}$ Similarly, we would propose that BDR testing is interpreted with caution, and that it is considered in its clinical context because a large proportion of patients with asthma and COPD will have values within the healthy range.

Contributors All authors contributed to the drafting of this editorial. MW undertook the statistical analyses.

Competing interests None.

Provenance and peer review Commissioned; internally peer reviewed.
Published Online First 12 June 2012

Thorax 2012:67:667-668.

doi:10.1136/thoraxjnl-2012-201966

\section{REFERENCES}

1. The Global Strategy for Asthma Management and Prevention, Global Initiative for Asthma (G/NA). 2011. http://www.ginasthma.org

2. British Thoracic Society, Scottish Intercollegiate Guidelines Network. British Guideline on the Management of Asthma: A national clinical guideline. Thorax 2008;63:(Suppl IV): i16-18.

3. Tan W, Vollmer W, Lamprecht B, et al. Worldwide patterns of bronchodilator responsiveness: results from the Burden of Obstructive Lung Disease (BOLD) Study. Thorax 2012;67:718-26.

4. Pellegrino R, Viegi G, Brusasco V, et al. Interpretative strategies for lung function tests. Eur Respir $\mathrm{J}$ 2005;26:948-68.

5. Brand PL, Quanjer PH, Postma DS, et al. Interpretation of bronchodilator response in patients with obstructive airways disease. The Dutch Chronic Non-Specific Lung Disease (CNSLD) Study Group. Thorax

1992;47:429-36.

6. Kesten S, Rebuck AS. Is the short-term response to inhaled beta-adrenergic agonist sensitive or specific for distinguishing between asthma and COPD? Chest 1994:105:1042-5.

7. Richter DC, Joubert JR, Nell H, et al. Diagnostic value of post-bronchodilator pulmonary function testing to distinguish between stable, moderate to severe COPD and asthma. Int $J$ Chron Obstruct Pulmon Dis 2008;3:693-9.

8. Anthonisen NR, Lindgren PG, Tashkin DP, et al. Bronchodilator response in the lung health study over 11 yrs. Eur Respir J 2005;26:45-51.

9. Calverley PM, Burge PS, Spencer S, et al. Bronchodilator reversibility testing in chronic obstructive pulmonary disease. Thorax 2003;58:659-64.

10. Hanania NA, Celli B, Donohue JF, et al. Bronchodilator reversibility in COPD. Chest 2011;140:1055-63.

11. Travers J, Marsh S, Williams M, et al. External validity of randomised controlled trials in asthma: to whom do the results of the trials apply? Thorax 2007:62:219-23.

12. Travers J, Marsh S, Caldwell B, et al. External validity of randomized controlled trials in COPD. Respir Med 2007;101:1313-20.

13. Postma DS, Brusselle G, Bush A, et al. I have taken my umbrella, so of course it does not rain. Thorax 2012:67:88-9. 